\title{
TITLE:
}

\section{Influence of potential grazers on picocyanobacterial abundance in Lake Biwa revealed with empirical dynamic modeling}

\section{AUTHOR(S):}

Cai, Ji; Hodoki, Yoshikuni; Ushio, Masayuki; Nakano, Shin-ichi

\section{CITATION:}

Cai, Ji ... [et al]. Influence of potential grazers on picocyanobacterial abundance in Lake Biwa revealed with empirical dynamic modeling. Inland Waters 2020, 10(3): 386-396

\section{ISSUE DATE:}

2020

URL:

http://hdl.handle.net/2433/267533

\section{RIGHT:}

This is an Accepted Manuscript of an article published by Taylor \& Francis in Inland Waters on 24 Feb 2020, available online: http://www.tandfonline.com/10.1080/20442041.2020.1711682; The full-text file will be made open to the public on 24 Feb 2021 in accordance with publisher's 'Terms and Conditions for Self-Archiving'.; This is not the published version. Please cite only the published version.この論文は出版社版でありません。引用の際には出版社版をご確認し 利用ください。 
1 Influence of potential grazers on picocyanobacterial abundance in

2 Lake Biwa revealed with empirical dynamic modeling

$3 \mathrm{Ji} \mathrm{Cai}^{1^{*}}$, Yoshikuni Hodoki ${ }^{1}$, Masayuki Ushio ${ }^{2,1,3}$, Shin-ichi Nakano ${ }^{{ }^{*}}$

$4 \quad{ }^{I}$ Center for Ecological Research, Kyoto University, Otsu 520-2113, Japan

$5 \quad{ }^{2}$ Hakubi Center, Kyoto University, Kyoto 606-8501, Japan

$6 \quad{ }^{3}$ PRESTO, Japan Science and Technology Agency, Kawaguchi 332-0012, Japan

7 *Mailing address: Center for Ecological Research, Kyoto University, Hirano-cho 2

8 chome, 509-3, Otsu, Shiga 520-2113, Japan.

9 Phone and Fax: +81-77-549-8239, +81-77-549-8201

10 E-mail: saikichi782@ecology.kyoto-u.ac.jp, nakano@ecology.kyoto-u.ac.jp 


\section{Influence of potential grazers on picocyanobacterial abundance in}

\section{Lake Biwa revealed with empirical dynamic modeling}

38 Picocyanobacteria, a diverse group of cyanobacteria defined by cell sizes of less than 2

$39 \mu \mathrm{m}$, are numerous and ubiquitous in freshwater and marine ecosystems (Stockner and

40 Antia 1986; Stockner 1988). Despite their small size, these photoautotrophic organisms

Picocyanobacteria in lakes generally occur as single cells (single-celled picocyanobacteria; SPcy) or colonies (colonial picocyanobacteria; CPcy), and the latter form has been considered an adaption to grazing pressure. In addition to direct effects of grazing, grazers may also have important indirect effects on picocyanobacteria, such as those from nutrient regeneration and trophic cascades. Interactions between picocyanobacteria and their grazers in lakes can thus be complex and difficult to predict. In the present study, we aimed to evaluate the influence of various grazers on SPcy and CPcy in Lake Biwa, Japan. We followed seasonal changes in the abundances of SPcy, CPcy, and their potential grazers biweekly over two years. The data collected were analyzed using empirical dynamic modeling (EDM), a model-free, nonlinear time-series method. We found that heterotrophic nanoflagellates (HNF), rotifers (Keratella, Polyarthra, and Trichocerca), cladocerans, and copepods played important and differing roles in controlling the abundances of SPcy and CPcy. Notably, HNF had an apparent positive influence on SPcy abundance, despite being considered major consumers of SPcy. This result suggested that the enhancement of SPcy growth due to nutrient regeneration by HNF might exceed losses from mortality due to grazing by HNF. EDM also suggested that colony formation by picocyanobacteria may be unidirectional, with SPcy tending to form CPcy. Our findings show that the seasonal dynamics of SPcy and CPcy in Lake Biwa are influenced by a variety of grazers, which may play differing ecological roles in the aquatic food web.

Keywords: empirical dynamic modeling, grazers, heterotrophic nanoflagellates, indirect effects, picocyanobacteria

\section{Introduction}


41 contribute largely to phytoplankton biomass and primary production, and play important

42 roles in aquatic ecosystems (Weisse 1993). In freshwaters, single-celled

43 picocyanobacteria (SPcy) dominate in oligotrophic environments and are mainly

44 represented by the genera Synechococcus and Cyanobium (Fogg 1995; Sanchez-

45 Baracaldo et al. 2005). Colonial picocyanobacteria (CPcy) are also common and often

46 abundant in meso-eutrophic environments (Stockner 1991; Stockner et al. 2000). They

47 consist of colonial species (e.g., Aphanothece, Aphanocapsa, Cyanodictyon) and

48 microcolonies formed by SPcy (Passoni and Callieri 2000; Callieri et al. 2012).

49 Understanding how the abundances of picocyanobacterial populations are

50 controlled by grazers is essential to elucidating their ecology. Grazing has been

51 considered a key top-down control process affecting SPcy abundance (Horn and Horn

52 2008). Small protists such as heterotrophic nanoflagellates (HNF) and ciliates are

53 considered the major consumers of SPcy (Stockner and Antia 1986; Šimek et al. 1995

54 and 1997; Sanders et al. 2000). An uptake of nearly $80 \%$ of the carbon produced by

55 SPcy was estimated for HNF and ciliates in an oligotrophic lake (Callieri et al. 2002).

56 Metazoan zooplankton are also important grazers of SPcy. Filter feeders such as

57 planktonic rotifers (e.g., Keratella, Polyarthra) and cladocerans (e.g., Daphnia,

58 Bosmina) can feed on pico-sized particles and thus consume SPcy (Gophen and Geller

59 1984; Weisse 1993; Ronneberger 1998; Callieri et al. 2012). Copepods are also efficient

60 SPcy grazers, even when alternative foods are available (Motwani and Gorokhova

61 2013). By contrast, CPcy appear to be resistant to grazing (Blomqvist 1996). It has been

62 suggested that colony formation by picocyanobacteria may act as an anti-grazing

63 strategy (Callieri et al. 2012). Grazing experiments have shown that some strains of

64 Synechococcus could form microcolonies when co-cultivated with HNF (Callieri et al. 
65 2016). Huber et al. (2017) demonstrated that grazing by Bosmina favored the

66 dominance of Cyanodictyon over SPcy. However, zooplankton such as Daphnia have

67 the ability to ingest particles up to tens of micrometers in size (Ronneberger 1998), and

68 thus small colonies of CPcy may be edible to such large grazers (Van Donk et al. 2011).

69 Grazers also play other important roles in controlling the abundances of

70 picocyanobacteria based on indirect interactions such as nutrient regeneration and

71 trophic cascades. Heterotrophic protists and metazoan zooplankton can excrete nitrogen

72 and phosphorus and thereby support the growth of phytoplankton (Johannes 1965;

73 Moegenburg and Vanni 1991; Nakano 1994a, b, c). Indeed, Callieri et al. (2004)

74 reported a significant increase in picocyanobacterial photosynthetic efficiency in the

75 presence of Daphnia grazing. In addition, predator-prey relationships exist among HNF,

76 ciliates, rotifers, cladocerans, and copepods (Arndt 1993; Sanders et al. 1994; Suzuki et

77 al. 1999; Nakano et al. 2001; Christoffersen and Gonzalez 2003; Brandl 2005), and

78 therefore the abundances of picocyanobacteria may be affected indirectly through

79 trophic cascades of these grazers (Wickham 1995; Sundt-Hansen et al. 2006). Taking

80 the direct effects of grazing into consideration, interactions between picocyanobacteria

81 and grazers in nature can thus be highly complex and difficult to predict.

82 To elucidate the influence of potential grazers on picocyanobacteria, we carried

83 out a two-year study in Lake Biwa, Japan, focusing on the differing ecological

84 properties of SPcy and CPcy. We collected samples biweekly and followed seasonal

85 changes in abundances of picocyanobacteria (SPcy and CPcy) and their potential

86 grazers (HNF, ciliates, rotifers, cladocerans, and copepods). Finally, we applied

87 empirical dynamic modeling (EDM), which is a model-free, nonlinear time-series

88 analysis method, to the time-series data collected. EDM was developed to specifically 
89 analyze the dynamics of nonlinear systems such as ecosystems, where traditional linear

90 tools are not applicable. Thus, this method is suitable for the analysis of the nonlinear,

91 state-dependent behaviors of picocyanobacteria observed in our study system. The main

92 objectives of the present study are two-fold: 1) identification of potential grazers that

93 affect SPcy and CPcy abundances under natural conditions, and 2) quantification of the

94 overall effects of various grazers on SPcy and CPcy abundances using EDM.

\section{Methods}

\section{Sample collection and measurement of environmental variables}

97 Sample collection was conducted biweekly at observation site Ie-1 (35 $12^{\prime} 58^{\prime \prime} \mathrm{N}$;

98 135 59'55"E; maximum depth, $73 \mathrm{~m}$ ) in the north basin of Lake Biwa (Mukherjee et al.

99 2017) from July 2015 to June 2017. Vertical profiles of water temperature, chlorophyll

$100 a(\mathrm{Chl}-a)$ concentration and photosynthetically active radiation (PAR) throughout the

101 water column were obtained using a CTD profiler (SBE-911 plus; Sea Bird Electronics,

102 Sea-logger, WA, USA). In addition, samples for analysis of dissolved inorganic

103 nitrogen (DIN) and dissolved inorganic phosphorus (DIP) were collected monthly at

104 depths of 0, 5, 10 and $20 \mathrm{~m}$ from August 2015 to July 2016. $\mathrm{NH}_{4}-\mathrm{N}$ concentrations were

105 measured using a sensitive fluorometric assay (Holmes et al. 1999). Concentrations of

$106 \mathrm{NO}_{2}-\mathrm{N}, \mathrm{NO}_{3}-\mathrm{N}$ and DIP were analyzed using an AACS-II autoanalyzer

107 (BRAN+LUEBBE).

108 Samples of picocyanobacteria, protists and metazoan zooplankton were

109 collected from depths of $0,5,10,15$ and $20 \mathrm{~m}$ with a 5 L Niskin sampler (General

110 Oceanics, Miami, USA). All samples were collected at around the same time of day

111 (10:00 to 12:00 h). For picocyanobacteria, unfiltered water samples were collected. For 
$112 \mathrm{HNF}$, water samples were prefiltered using a plankton net with a mesh size of $20 \mu \mathrm{m}$,

113 and the filtrate was collected. After collection, $100 \mathrm{ml}$ of each water sample was fixed

114 with glutaraldehyde at a final concentration of $1 \%$ for enumeration of picocyanobacteria

115 and $\mathrm{HNF}$, and the fixed samples were then stored in the dark at $4{ }^{\circ} \mathrm{C}$. For other

116 zooplankton (ciliates, rotifers, cladocerans, and copepods), $10 \mathrm{~L}$ of lake water was

117 concentrated to $100 \mathrm{ml}$ using a plankton net with mesh size $20 \mu \mathrm{m}$, then fixed with $5 \%$

118 acid Lugol's solution and stored in the dark.

\section{Sample treatment and plankton enumeration}

120 For the enumeration of picocyanobacteria, fixed samples of 1-10 ml were filtered

121 through $0.2 \mu \mathrm{m}$ polycarbonate membrane filters to retain cells. Duplicate filters were

122 prepared for each sample. An epifluorescence microscope (Olympus BX53, 1000x) was

123 used to enumerate SPcy and CPcy cells under green excitation (530-550 nm). At least

124100 cells or 50 fields were counted from each filter. For the enumeration of HNF, fixed

125 samples of $30-50 \mathrm{ml}$ were filtered through $0.8 \mu \mathrm{m}$ polycarbonate membrane filters.

126 HNF cells on the filter were stained with primulin according to methods in Caron

127 (1983) and enumerated under ultraviolet excitation. Nanoflagellates that exhibited no

128 apparent red chlorophyll fluorescence under green excitation were identified as HNF.

129 To count metazoan zooplankton, fixed samples were poured into $100 \mathrm{ml}$

130 cylinders and concentrated through natural sedimentation for at least $48 \mathrm{~h}$. One $\mathrm{ml}$ of

131 the concentrated sample was then loaded onto a Sedgewick-Rafter counting chamber

132 (Pyser-SGI Limited, British) and checked under an optical microscope (Olympus BX51,

133 100x). Each sample was counted twice. 


\section{Time series and state space reconstruction (SSR)}

135 Time series can be defined as any set of sequential observations of the system state, and

136 the dynamic behaviors can be delineated as a trajectory of a state over time in a

137 multidimensional state space by plotting time series. Time series taken from ecosystems

138 can be used to trace out trajectories of the system, which provide information on

139 ecosystem dynamics. For example, if one has performed sequential observations on a

140 three-species ecological system, e.g., grasses (primary producer), rabbits (consumer)

141 and foxes (predator), then the dynamics of the three-species system can be reconstructed

142 by plotting time series of grasses, rabbits, and foxes along the $x, y$, and $z$ axis,

143 respectively, in a three-dimensional state space. The motion of the three-dimensional

144 vectors can be understood as the system behavior.

145 In a natural ecosystem, however, it is usually impossible to collect time series of

146 all potentially important variables involved in a target system. Fortunately, Takens

147 (1981) offered a theoretical basis to solve this problem: a mathematical theorem,

148 Takens' embedding theorem, demonstrated that a shadow version of the attractor can be

149 reconstructed by a single observed time series. In other words, delineation of

150 trajectories, originally constructed using multivariables, can be possible even if a time

151 series is available only for a single variable (Sauer et al. 1981; Takens 1981). To embed

152 such a single time series, vectors in the putative phase space are formed from time-

153 delayed values of the time series, $\{x(t), x(t-\tau), x(t-2 \tau) \ldots, X(t-[E-1] \tau)\}$, where $E$ is the

154 embedding dimension, and $\tau$ is the time lag. This procedure, the reconstruction of the

155 original dynamics, is known as State Space Reconstruction (SSR). 


\section{Empirical dynamics modeling (EDM)}

157 EDM, a time-series analytical framework rooted in SSR and designed specifically for

158 the analysis of nonlinear dynamics such as ecosystem processes (Sugihara et al. 2012;

159 Ye et al. 2015; Deyle et al. 2016), was applied to our time-series data. Because EDM

160 recovers dynamics directly from time series using SSR, it does not assume any set of

161 equations governing the system, and thus is suitable for analyzing complex systems, for

162 which it is often difficult to make reasonable $a$ priori assumptions about their

163 underlying mechanisms. EDM provides tools for various purposes, including the

164 identification of causal factors and quantification of interaction strengths in nonlinear

165 systems where traditional linear statistical tools are not applicable, and has been

166 recently proven effective for analyzing the dynamics of natural complex ecosystems

167 (Ye et al. 2015; Ushio et al. 2018). The analysis workflow in the present study was as

168 follows: first, causal links between picocyanobacteria and other variables (e.g., water

169 temperature, Chl- $a$, or HNF) were identified using convergent cross mapping (CCM;

170 Sugihara et al. 2012); second, when causal links were identified, the interaction

171 strengths between variables were quantified using the multivariate S-map method

172 (Deyle et al. 2016). Detailed descriptions of CCM and the multivariate S-map are

173 available in previous studies (Sugihara et al. 2012; Deyle et al. 2016; Chang et al. 2017;

174 Ushio et al. 2019). Considering the thermal stratification and vertical migration of the

175 plankton community, we used the average of time-series data collected from 0 to $20 \mathrm{~m}$

176 in our analyses. Data were normalized to a zero mean and unit variance prior to EDM

177 analysis. The library size (i.e., the length of time-series data) of most variables was 48,

178 whereas that of CPcy was 38. 
First, CCM was applied to detect causal links. Briefly, if two variables are

180 causally related in a dynamic system, they should share the same attractor, making it

181 possible to predict the values of the causal variable by using the reconstructed state

182 space of the effect variable (Sugihara et al. 2012). CCM quantifies how well an effect

183 variable predicts the values of a putative causal variable, and the forecasting accuracy

184 (i.e., cross map skill) and its convergence against the library size are important criteria

185 for determining causality (for more details, see Sugihara et al. 2012). An essential

186 parameter of CCM, the optimal embedding dimension $(E)$, was determined using

187 simplex projection (Sugihara and May 1990). Simplex projection can be used to find the

188 optimal value of $E$ by identifying which $E$ maximizes the forecasting accuracy of a

189 given time series. According to simplex projection, the optimal $E$ for the time series of

190 SPcy and CPcy were 2 and 3, respectively. Another important parameter, time lag $(\tau)$ in

191 the lagged coordinate embedding, was set to 1 following a previous study (Chang et al.

192 2017), which corresponds to 2 weeks in our time series. Due to the time-lagged causal

193 relationship, preliminary CCM was conducted to find the optimal cross-map lag $\left(t_{p}\right.$,

194 time to prediction) for each causal variable. The optimal $t_{p}$ value which maximized the

195 forecasting accuracy within the range of 0 to -6 (i.e., between now and three months

196 ago) was chosen. Then, CCM was performed to calculate cross map skill and thus

197 identify causal variables that affect SPcy and CPcy. Fisher's z-test and surrogate test

198 were successively applied to determine whether the cross map skill was statistically

199 significant (Chang et al. 2017). Fisher's z-test examines whether the cross map skill

200 obtained using the maximal library length is significantly higher than that obtained

201 using the minimal library length (i.e., convergence). Surrogate test examines whether 
202 the cross map skill is significantly different from the null model expectation generated

203 using surrogate time series.

204 Second, based on the set of significant causal variables identified through CCM,

205 the multivariate S-map was built to quantify the influence of each variable on SPcy or

206 CPcy, which was approximated using partial derivatives of the causal variables. Time-

207 series data of the effect variable (SPcy or CPcy) and significant causal variables with

208 lag equal to the optimal $t_{p}$ were used to reconstruct the state space. For example, if the

209 variables $Y$ and $Z$ influence variable $X$ with $t_{p}$ of -2 and -3 , respectively, the state space

210 is reconstructed as follows: $\{X(t), X(t-1), \ldots, X(t-[E-1]), Y(t-1), Z(t-2)\}$, and $X(t+1)$ is

211 predicted using the multivariate S-map. In the multivariate S-map analysis, the

212 nonlinear parameter $(\theta)$ that minimizes the forecasting error was chosen according to

213 previous studies (Deyle et al. 2016; Ushio et al. 2018).

214 Lastly, Spearman's correlation analysis was conducted to infer potential

215 relationships between the abundances of picocyanobacteria and concentrations of

216 nutrients (DIN and DIP). This method was used because the lengths of time series of

217 nutrients $(\mathrm{N}=13)$ were not sufficient for EDM. All analyses described above were

218 carried out using R v3.4.3 (R Development Core Team, 2018). EDM was performed

219 using the "rEDM" package (version 0.7.2, Ye et al. 2015), and the step-by-step tutorial

220 is available at https://ha0ye.github.io/rEDM/index.html.

\section{Results}

\section{Seasonal profiles of water temperature, Chl-a, and nutrients}

223 In Lake Biwa, thermal stratification was pronounced from June to October (the

224 stratification period) with a thermocline between 15 and 30 m (Fig. 1a). In August and 
225 September, water temperature in the epilimnion reached as high as $29.8^{\circ} \mathrm{C}$. Water

226 column started mixing in November and circulated totally from February to March (the

227 mixing period). During the mixing period, the average ( \pm standard deviation) water

228 temperature was $8.4 \pm 0.5{ }^{\circ} \mathrm{C}$.

229 The annual mean concentration of Chl- $a$ in the euphotic zone (from 0 to $20 \mathrm{~m}$,

230 calculated by PAR, data not shown) was $2.65 \pm 1.85 \mu \mathrm{g} \mathrm{L}^{-1}$ (Fig. 1b). Elevated Chl- $a$

231 concentrations ( $>5 \mu \mathrm{g} \mathrm{L}^{-1}$ ) were recorded several times: from April to May 2016, from

232 November 2016 to January 2017 and from May to June 2017. The mean concentration

233 of DIN was $1.64 \pm 1.26 \mu \mathrm{mol} \mathrm{L}{ }^{-1}$. DIN was depleted in the epilimnion during the

234 stratification period but relatively high at other times (Fig. S1a). DIP concentrations

235 were low and remained nearly constant across depths and seasons, with an average of

$2360.0045 \pm 0.0025 \mu \mathrm{mol} \mathrm{L}{ }^{-1}$ (Fig. S1b).

\section{Seasonal dynamics of picocyanobacteria and potential grazers}

238 The annual average SPcy abundance in the water column above $20 \mathrm{~m}$ was $5.64 \pm 9.00 \times$

$23910^{4}$ cells $\mathrm{mL}^{-1}$ during the study period (Fig. 2a). High cell densities (up to $4.50 \times 10^{5}$

240 cells $\mathrm{mL}^{-1}$ ) were recorded in June and August 2016. Generally, SPcy were highly

241 abundant $\left(>10^{5}\right.$ cells $\left.\mathrm{mL}^{-1}\right)$ throughout the stratification period and were mainly

242 distributed in the epilimnion. During the mixing period, SPcy density decreased to

243 around $10^{2}$ cells $\mathrm{mL}^{-1}$ and the cells were almost homogeneously distributed throughout

244 the water column.

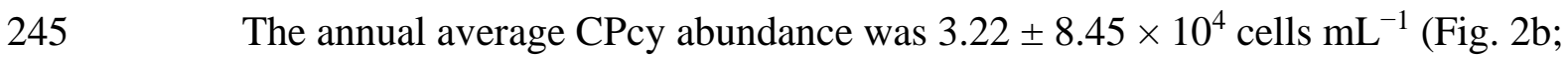

246 calculated using data collected from July 2016 to June 2017, as data from 2015 were

247 incomplete). CPcy density increased dramatically from $10^{3}$ to $>3 \times 10^{5}$ cells $\mathrm{mL}^{-1}$ in the

248 epilimnion at the beginning of July. The majority of CPcy were observed near the 
249 thermocline after 2 weeks and the greatest cell density (up to $4.54 \times 10^{5}$ cells $\mathrm{mL}^{-1}$ ) was

250 recorded at a depth of $15 \mathrm{~m}$ in mid-July 2016. From September onward, CPcy density

251 declined rapidly to $<10^{3}$ cells $\mathrm{mL}^{-1}$ and became undetectable during the mixing period.

252 HNF were observed throughout the year in the water column, with an average

253 cell density of $7.86 \pm 6.44 \times 10^{2}$ cells $\mathrm{mL}^{-1}$ (Fig. S2a). Generally, HNF were abundant

$254\left(>10^{3}\right.$ cells $\left.\mathrm{mL}^{-1}\right)$ in the epilimnion during stratification periods and remained scarce

$255\left(>10^{2}\right.$ cells $\left.\mathrm{mL}^{-1}\right)$ during mixing periods. By contrast, ciliates were not a major protistan

256 group in Lake Biwa (Fig. S2b). At most times, ciliates were at low abundance ( $<10$ cells

$257 \mathrm{~L}^{-1}$ ) or even below the detection limit, with an annual average cell density of $51.7 \pm$

258153.8 cells L ${ }^{-1}$. Nevertheless, the genera Epistylis and Codonella sometimes formed

259 transient blooms in summer or autumn with densities greater than $10^{3}$ cells $\mathrm{L}^{-1}$.

260 We observed no clear seasonal or vertical trends in the abundances of rotifers,

261 cladocerans, and copepods. These grazers could be abundant in spring, summer or

262 autumn at different depths (Fig. S2c-e). The annual average density of rotifers was

$263111.6 \pm 124.5$ individuals $\mathrm{L}^{-1}$. Rotifers in Lake Biwa were highly diverse, so we also

264 recorded seasonal changes in their genus-level composition (Fig. S3). The dominant

265 genera during the study period were Polyarthra, Keratella and Trichocerca, accounting

266 for $55.1 \%, 11.5 \%$, and $10.8 \%$ of total rotifer abundance, respectively. Average densities

267 of cladocerans and copepods were $13.2 \pm 15.6$ and $58.8 \pm 59.1$ individuals $\mathrm{L}^{-1}$,

268 respectively. The dominant genera of cladocera were Daphnia and sometimes Bosmina,

269 whereas copepods were dominated by Eodiaptomus japonicus.

\section{Results of EDM and correlation analysis}

271 According to CCM, temperature, HNF, cladocera, copepod, and Keratella were

272 identified as causal variables that affected seasonal changes in the abundance of both 
273 SPcy and CPcy, whereas Polyarthra affected only SPcy and Trichocerca affected only

274 CPcy (Table 1; see details in Fig. S4 and S5). In addition, we also found causal links

275 between SPcy and CPcy. No significant causal link was found between SPcy and other

276 variables such as Chl- $a$ concentration, ciliates or non-dominant rotifers (e.g., Pleosoma,

277 Pompholyx), or between CPcy and those variables (data not shown).

278 The influences of causal variables on SPcy and CPcy were then quantified using

279 the multivariate S-map (Fig. 3; see Table S1 for optimal parameters of the multivariate

280 S-map). Positive and negative values of interaction strengths can be interpreted as an

281 effect variable tending to increase and decrease, respectively, in response to the increase

282 in a causal variable (Deyle et al. 2016). Although the multivariate S-map method

283 enables the calculation of time-varying interaction strengths, we used time-averaged

284 values of interaction strengths to evaluate the overall effects of causal variables on

285 picocyanobacterial abundance for convenience and simplicity (Table 1; Fig. 4).

286 Therefore, temperature, HNF, and Polyarthra had positive effects on SPcy, whereas

287 CPcy, Keratella, and cladocera negatively affected SPcy abundance. And copepods had 288 a moderating effect on SPcy. On the other hand, SPcy, HNF, Trichocerca, and copepod 289 had positive effects on CPcy abundance, whereas temperature, Keratella, and cladocera 290 had negative effects on CPcy.

291 Lastly, potential relationships among SPcy, CPcy, DIN, and DIP were examined

292 using Spearman's correlation analysis. The results showed that DIN was negatively

293 correlated with SPcy and CPcy $\left(\mathrm{r}_{\mathrm{s}}=-0.668, \mathrm{p}<0.001 ; \mathrm{r}_{\mathrm{s}}=-0.734, \mathrm{p}<0.001\right.$,

294 respectively). DIP was negatively correlated with CPcy $\left(\mathrm{r}_{\mathrm{s}}=-0.528, \mathrm{p}<0.001\right)$, but not

295 significantly correlated with SPcy $\left(\mathrm{r}_{\mathrm{s}}=0.092, \mathrm{p}=0.516\right)$. 


\section{Discussion}

297 In the present study, we applied EDM for exploring the environmental variables and

298 organisms that are potential drivers of the seasonal dynamics of picocyanobacteria.

299 Interaction strengths estimated using the multivariate S-map revealed how these

300 variables affect picocyanobacterial abundance. In many cases, both positive and

301 negative values were obtained simultaneously, suggesting complex relationships

302 between the causal variable and SPcy or CPcy. The influence by one causal variable on

303 SPcy or CPcy abundance (i.e., the average of interaction strengths) should be regarded

304 as a "net" interaction strength. In other words, the time-averaged interaction strength

305 calculated in the present study indicates whether positive "bottom-up" effects were

306 larger than negative "top-down" effects or not (Deyle et al. 2016).

\section{Effects of environmental variables on picocyanobacteria}

308 The positive influence of temperature on SPcy as revealed through EDM (Fig. 3a)

309 indicates that temperature played an important role in increasing the abundance of

310 picocyanobacteria (Vörös et al. 2009; Jodłowska and Śliwińska 2014). By contrast,

311 CPcy was negatively affected by temperature (Fig. 3b), despite being reported to

312 increase dramatically in the warm summer months (Callieri et al. 2012). This result may

313 be caused by sinking due to the large colony sizes of CPcy (Deng et al. 2016). After

314 forming transient blooms near the water surface, CPcy immediately sank to the

315 metalimnion (15-20 m), where water temperature was relatively low during the

316 stratification period (Fig. 1a and 2b). On the other hand, we did not find a relationship

317 between Chl- $a$ concentration and picocyanobacterial abundance. Although

318 picocyanobacteria could be dominant ( $45 \%$ of total Chl- $a$ ) during the stratification 
319 period, they were not a major group in the phytoplankton community during other parts

320 of the year in Lake Biwa (<5\% of total Chl- $a$ in other months; Nagata 1986). Lastly,

321 the negative correlations found between DIN or DIP and picocyanobacterial abundance

322 suggested that low nutrient availability facilitated the dominance of SPcy (Nagata 1986;

323 Schallenberg and Burns 2001; Callieri 2008), and that nutrient limitation could be one

324 of the factors inducing colony formation (Callieri et al. 2012).

\section{Relationships between single cells and colonies}

326 Some strains of SPcy are known to form microcolonies under certain conditions such as

327 ultraviolet radiation or grazing pressure (Jezberová and Komárková 2007; Callieri et al.

328 2011; Callieri et al. 2016). Conversely, some CPcy genera have single-cell stages in

329 their life histories (Komárková and Šimek 2003) and many genera in the order

330 Synechococcales that were originally described as colonial lose their mucilaginous

331 envelopes in cultivation (Komárek et al. 2014). Therefore, transformation between

332 single cells and colonies may occur frequently in lakes. Fortunately, we found

333 significant causal links between SPcy and CPcy, suggesting that they were affected by

334 each other. Furthermore, the multivariate S-map results suggested that SPcy could have

335 enhanced the abundance of CPcy, whereas CPcy decreased that of SPcy (Fig. 4).

336 Therefore, the transformation of the morphology of picocyanobacteria is likely

337 unidirectional in Lake Biwa, with SPcy tending to form CPcy.

\section{Effects of protists on picocyanobacteria}

339 HNF have been regarded as key grazers of SPcy that contribute strongly to the latter's

340 mortality losses (Nagata 1988; Callieri et al. 2002), and thus HNF are expected to have

341 negative effects on SPcy abundance. However, the opposite result was obtained from 
342 EDM, with HNF increasing SPcy abundance rather than reducing them (Fig. 4). A

343 possible explanation for this is the enhancement of SPcy growth due to nutrient

344 regeneration by HNF exceeding mortality losses due to grazing by HNF. This is

345 consistent with the results in previous studies (Ferrier-Pages and Rassoulzadegan 1994;

346 Selph et al. 2003), though it is impossible to quantify the amount of nutrients excreted

347 respectively by HNF or other grazers from nutrient samples we collected.

348 The other possible explanation is the presence of trophic cascade, as HNF fall

349 within the food size ranges of a variety of predators and are vulnerable to predation in

350 aquatic environments (Pace et al. 1998; Nakano et al. 2001). We investigated the

351 influence of putative predators on HNF using EDM, and found that Polyarthra and

352 cladocera showed negative influences on HNF abundance (Table S2), suggesting the

353 presence of top-down controls on HNF by these predators (Pourriot 1977; Stemberger

354 and Gilbert 1985; Jürgens et al. 1996). So it is likely that grazing pressure of HNF on

355 picocyanobacteria can be suppressed by predation of Polyarthra and cladocerans.

356 Furthermore, HNF were enumerated at the community level in the present study, and

357 grazing on SPcy by HNF is species-specific (Callieri et al. 2012). Therefore, the HNF

358 species that prey on SPcy could be minor in our samples, which could result in the

359 moderate influence of SPcy on HNF (Table S2).

360 On the other hand, the positive effect on CPcy abundance by HNF (Fig. 4)

361 suggested that HNF play an important role in stimulating colony formation by

362 picocyanobacteria, possibly through grazing on single cells, as previously reported

363 (Callieri et al. 2016). Indeed, microcolony-forming bacteria generally cannot be

364 consumed by HNF due to their large size (Hahn et al. 2000), and we found an apparent 
negative effect of CPcy on HNF (Table S2), which suggests that HNF are unlikely to graze on CPcy.

Ciliates are also important grazers of picocyanobacteria (Šimek et al. 1995 and 1997), but EDM did not show a significant causal link between their abundance and that of SPcy or CPcy. Ciliates may not be involved in controlling picocyanobacterial abundance, due to their low abundance in the north basin of Lake Biwa (Yoshida et al. 2001b).

\section{Effects of metazoan zooplankton on picocyanobacteria}

The relationships between metazoan zooplankton and picocyanobacteria can be more complex because they are both potential grazers of picocyanobacteria and predators of HNF and small zooplankton. For example, rotifers feed significantly on nanoflagellates and small ciliates (Arndt 1993), whereas cladocerans prey upon a wide range of food particle sizes $(1-50 \mu \mathrm{m})$ that includes small protists (Gophen and Geller 1984; Stockner and Porter 1988; Sanders et al. 1994). Copepods use a variety of hunting and feeding techniques, enabling them to prey on diverse planktonic animals (Suzuki et al. 1999; Brandl 2005). The influence of rotifers, cladocerans, and copepods on SPcy or CPcy can thus be interpreted as the synergistic effects of grazing, nutrient regeneration, and trophic cascades. In addition, we also conducted EDM analyses to investigate whether and how these grazers could be affected by other variables (Table S2). However, potential causal variables of metazoan zooplankton, such as abundances of bacteria, phytoplankton and their predators, are not available. The reconstructed dynamics of metazoan zooplankton might not be reasonably resolved, and thus the interaction strengths calculated by the multivariate S-map might be counter-intuitive and difficult to explain. Therefore, detailed discussion on influences of causal variables on metazoan 
389 zooplankton can be speculative and should be avoided as possible.

390 Rotifers that have been previously reported to prey on picocyanobacteria are

391 Keratella and Polyarthra (Callieri et al. 2012), both of which were dominant genera in

392 Lake Biwa (Yoshida et al. 2001b). Keratella showed apparent top-down control on

393 picocyanobacterial abundance (Fig. 4), indicating that they may be effective grazers of

394 both SPcy and CPcy (Pourriot 1977; Callieri et al. 2012; Table S2, positive influence of

395 CPcy on Keratella). The positive effect of Polyarthra on SPcy (Fig. 4) suggested that

396 Polyarthra may enhance SPcy abundance through preying on HNF, as discussed

397 previously. The bacterivorous rotifer Trichocerca enhanced the abundance of CPcy

398 (Fig. 4), and the negative influence of CPcy on Trichocerca may suggest that CPcy

399 were not grazed by Trichocerca (Table S2). However, it is unclear whether grazing

400 pressure from Trichocerca plays a role in inducing colony formation, as they had no

401 effect on SPcy (Table 1). Overall, rotifers have seldom been investigated as grazers of

402 picocyanobacteria, and therefore further research is needed to clarify the food chain

403 between rotifers and picocyanobacteria.

404 Cladocerans are well-known grazers of SPcy (Callieri et al. 2012), and they had

405 an apparent negative influence on SPcy abundance (Fig. 4). Similar to the rotifer

406 Keratella, cladocerans (mainly Daphnia) induced the decrease in CPcy abundance (Fig.

407 4), suggesting that they graze on CPcy. Although the CPcy found during the present

408 study generally had large colony sizes (up to several hundred $\mu \mathrm{m}$ ), microcolonies

409 ranging from several to tens of micrometers can be eaten by cladocerans (Ronneberger

410 1998; Table S2, positive influence of CPcy on cladocera).

411 The effect of copepods on SPcy abundance was nearly moderate, despite their

412 ability to ingest SPcy effectively (Fig. 4; Motwani and Gorokhova 2013; Table S2, 
413 positive influence of SPcy on copepod). A possible reason for this finding is that the

414 negative effects of grazing were offset by positive indirect effects, especially through

415 trophic cascades, as copepods represent the highest trophic level among grazers of

416 picocyanobacteria. A trophic cascade involving copepods may also be a major

417 contributor to their positive influence on CPcy (Fig. 4). Copepods increased the

418 abundance of CPcy, possibly by preying on microzooplankton such as Keratella

419 (Yoshida et al. 2001a) that have negative effects on CPcy abundance.

\section{Conclusions}

421 Increasing picocyanobacterial abundance along with climate change in future have been

422 indicated in oceans (Flombaum et al. 2013). In lakes, growing blooms of

423 picocyanobacteria also have been reported in recent years, and some species of

424 picocyanobacteria can produce harmful toxins and secondary metabolites thus causing

425 problems to public health (Jakubowska and Szeląg-Wasielewska 2015; Jasser and

426 Callieri 2016; Śliwińska-Wilczewska et al. 2018). Despite the increasing impacts of

427 picocyanobacteria on aquatic ecosystems, however, ecology of them remain largely

428 unclear. So far, few studies have been reported discussing the comprehensive impacts of

429 grazers on picocyanobacteria.

430 In the present study, we found that HNF, Keratella, Polyarthra, Trichocerca,

431 cladocerans and copepods had important impacts on SPcy and CPcy, and played various

432 roles in controlling their abundances (Fig. 4). Notably, we found that HNF might

433 stimulate the growth of SPcy through indirect positive effects such as nutrient

434 regeneration in excess of direct negative effects such as grazing, which is a novel result.

435 We also found that single cells of picocyanobacteria tended to form colonies, possibly

436 due to the positive effects of HNF, Trichocerca and copepods on CPcy. Our findings 
437 clearly show that natural seasonal dynamics of picocyanobacteria in Lake Biwa are

438 influenced by a variety of grazers, and that the influences of grazers in complex natural

439 food webs are often counter-intuitive. Furthermore, because SPcy and CPcy are

440 influenced by different grazers, they may thus play differing ecological roles in the

441 aquatic food web. It should be noticed that we did not conduct any in situ or laboratory

442 experiments to validate the results of the present study. Further research, especially in

443 situ manipulative experiments, is needed to elucidate the detailed interspecific

444 interactions among picocyanobacteria and their grazers.

446 Acknowledgements. We are grateful to Drs. Yukiko Goda and Tetsushi Akatsuka, the crew of 447 our sampling vessel "HASU", for providing technical assistance during sample collection. We 448 also thank Dr. Yusuke Okazaki, Dr. Indranil Mukherjee and Mr. Fujinaga Shohei for their 449 valuable help during the sampling. This work was partly supported by KAKENHI, Grants-in450 Aid for Scientific Research, [grant number 19H03302] from the Japan Society for the 451 Promotion of Science.

453 References

454 Arndt H. 1993. Rotifers as predators on components of the microbial web (bacteria, heterotrophic flagellates, ciliates) — a review. Hydrobiologia. 255/256: 231-

457 Blomqvist P. 1996. Late summer phytoplankton responses to experimental manipulations of nutrients and grazing in unlimed and limed Lake Njupfatet,

460 Brandl Z. 2005. Freshwater copepods and rotifers: predators and their prey.

$461 \quad$ Hydrobiologia. 546: 475-489.

462 Callieri C, Karjalainen SM, Passoni S. 2002. Grazing by ciliates and heterotrophic nanoflagellates on picocyanobacteria in Lago Maggiore, Italy. J Plankton Res. 24: 785-796. 
465 Callieri C, Balseiro E, Bertoni R, Modenutti B. 2004. Picocyanobacterial photosynthetic 466 efficiency under Daphnia grazing pressure. J Plankton Res. 26: 1471-1477.

467 Callieri C. 2008. Picophytoplankton in freshwater ecosystems: the importance of small468 sized phototrophs. Freshw Rev. 1: 1-28. Microbiol. 77: 7533-7540.

Callieri C, Cronberg G, Stcokner JG. 2012. Freshwater picocyanobacteria: single cells, microcolonies and colonial Forms. In: Whitton BA, editor. Ecology of Cyanobacteria II: Their Diversity in Time and Space. Berlin: Springer; p. 229269.

Callieri C, Amalfitano S, Corno G, Bertoni R. 2016. Grazing-induced Synechococcus microcolony formation: experimental insights from two freshwater phylotypes. FEMS Microbiol Ecol. 92: fiw154.

Caron DA. 1983. Technique for enumeration of heterotrophic and phototrophic nanoplankton, using epifluorescence microscopy, and comparison with other

482 Chang CW, Ushio M, Hsieh CH. 2017. Empirical dynamic modeling for beginners. Ecol Res. 32: 785-796.

484 Christoffersen K, Gonzalez JM. 2003. An approach to measure ciliate grazing on living heterotrophic nanoflagellates. Hydrobiologia. 491: 159-166.

Deng W, Cruz BN, Neuer S. 2016. Effects of nutrient limitation on cell growth, TEP production and aggregate formation of marine Synechococcus. Aquat Microb Ecol. 78: 39-49.

489 Deyle ER, May RM, Munch SB, Sugihara G. 2016. Tracking and forecasting ecosystem interactions in real time. Proc Biol Sci. 283(1822): 20152258.

491 Ferrier-Pages C, Rassoulzadegan F. 1994. Seasonal impact of the microzooplankton on pico- and nanoplankton growth rates in the northwest Mediterranean Sea. Mar Ecol Prog Ser. 108: 283-294.

494 Flombaum P, Gallegos JL, Gordillo RA, Rincón J, Zabala LL, Jiao N, Karl DM, Li WKW, Lomas MW, Veneziano D, et al. 2013. Present and future global 

distributions of the marine cyanobacteria Prochlorococcus and Synechococcus. Proc Natl Acad Sci USA. 110: 9824-9829.

Fogg GE. 1995. Some comments on picoplankton and its importance in the pelagic ecosystem. Aquat Microb Ecol. 9: 33-39.

Gophen M, Geller W. 1984. Filter mesh size and food particle uptake by Daphnia. Oecologia. 64: 408-412.

Hahn MW, Moore ERB, Höfle MG. 2000. Role of microcolony formation in the protistan grazing defense of the aquatic bacterium Pseudomonas sp. MWH1. Microb. Ecol. 39: 175-185.

Holmes RM, Aminot A, Kérouel R, Hooker BA, Peterson BJ. 1999. A simple and precise method for measuring ammonium in marine and freshwater ecosystems. Can. J. Fish. Aquat. Sci. 56: 1801-1809.

Horn H, Horn W. 2008. Bottom-up or top-down - how is the autotrophic picoplankton mainly controlled? Results of long-term investigations from two drinking water reservoirs of different trophic state. Limnologica. 38: 302-312.

Huber P, Diovisalvi N, Ferraro M, Metz S, Lagomarsino L, Llames ME, Royo-Llonch M, Bustingorry J, Escaray R, Acinas SG, et al. 2017. Phenotypic plasticity in freshwater picocyanobacteria. Environ Microbiol. 19: 1120-1133.

Jakubowska N, Szeląg-Wasielewska E. 2015. Toxic Picoplanktonic Cyanobacteria Review. Mar. Drugs.13: 1497-1518.

Jasser I, Callieri C. 2016. Picocyanobacteria - the smallest cell-size cyanobacteria. In: Meriluoto J, Spoof L, Codd GA, editors. Handbook on cyanobacterial monitoring and cyanotoxin analysis 1st edn. Chichester: Wiley; p. 19-27.

Jezberová J, Komárková J. 2007. Morphological transformation in a freshwater Cyanobium sp. induced by grazers. Environ Microbiol. 9: 1858-1862.

Jodłowska S, Śliwińska S. 2014. Effects of light intensity and temperature on the photosynthetic irradiance response curves and chlorophyll fluorescence in three picocyanobacterial strains of Synechococcus. Photosynthetica. 52: 223-232.

Johannes RE. 1965. Influence of marine protozoa on nutrient regeneration. Limnol Oceanogr. 10: 434-442. 
526 Jürgens K, Wickham SA, Rothhaupt KO, Santer B. 1996. Feeding rates of macro-and microzooplankton on heterotrophic nanoflagellates. Limnol. Oceanogr. 41: 1833-1839.

Komárek J, Kaštovský J, Mareš J, Johansen JR. 2014. Taxonomic classification of cyanoprokaryotes (cyanobacterial genera) 2014, using a polyphasic approach. Preslia. 86: 295-335.

Komárková J, Šimek K. 2003. Unicellular and colonial formations of picoplanktonic cyanobacteria under variable environmental conditions and predation pressure. Arch. Hydrobiol. Suppl. Algol. Stud. 109: 327-400.

Moegenburg SM, Michael JV. 1991. Nutrient regeneration by zooplankton: effects on nutrient limitation of phytoplankton in a eutrophic lake. J Plankton Res. 13: $573-588$.

Motwani NH, Gorokhova E. 2013. Mesozooplankton grazing on picocyanobacteria in the Baltic Sea as inferred from molecular diet analysis. PLoS One. 8: e79230.

Mukherjee I, Hodoki Y, Nakano S. 2017. Seasonal dynamics of heterotrophic and plastidic protists in the water column of Lake Biwa, Japan. Aquat Microb Ecol. 80: $123-137$.

Nagata T. 1986. The seasonal abundance and vertical distribution of the $<3-\mu \mathrm{m}$ phytoplankton in the north basin of Lake Biwa. Ecol Res. 1: 207-221.

Nagata T. 1988. The microflagellate-picoplankton food linkage in the water column of Lake Biwa, Japan. Limnol. Oceanogr. 33: 504-517.

Nakano S. 1994a. Carbon:nitrogen:phosphorus ratios and nutrient regeneration of a heterotrophic flagellate fed on bacteria with different elemental ratios. Arch Hydrobiol. 129: 257-271.

Nakano S. 1994b. Estimation of phosphorus release rate by bacterivorous flagellates in Lake Biwa. Jpn J Limnol. 55: 201-211.

Nakano S. 1994c. Rates and ratios of nitrogen and phosphorus by a bacterivorous flagellate. Jpn J Limnol. 55: 115-223.

Nakano S, Manage PM, Nishibe Y, Kawabata Z. 2001. Trophic linkage among heterotrophic nanoflagellates, ciliates and metazoan zooplankton in a hypereutrophic pond. Aquat. Microb. Ecol. 25: 259-270. 
Pace ML, Cole JJ, Carpenter SR. 1998. Trophic cascades and compensation: differential responses of microzooplankton in whole-lake experiments. Ecology. 79(1): 138152.

Passoni S, Callieri C. 2000. Picocyanobacteria single forms, aggregates and microcolonies: survival strategy or species succession?. Ver Internat Verein Limnol. 27: 1879-1883.

Pourriot R. 1977. Food and feeding habits of rotifers. Arch Hydrobiol Beih Ergebn Limnol. 8: 243-260.

R Development Core Team. 2018. R: A language and environment for statistical computing. R Foundation for Statistical Computing, Vienna, Austria. https://www.R-project.org/.

Ronneberger D. 1998. Uptake of latex beads as size-model for food of planktonic rotifers. Hydrobiologia. 387(388): 445-449.

Sanchez-Baracaldo P, Hayes PK, Blank CE. 2005. Morphological and habitat evolution in the cyanobacteria using a compartmentalization approach. Geobiology. 3: $145-165$.

Sanders RW, Leeper DA, King CH, Porter KG. 1994. Grazing by rotifers and crustacean zooplankton on nanoplanktonic protists. Hydrobiologia. 288: 167181.

Sanders RW, Berninger U, Lim EL, Kemp PF, Caron DA. 2000. Heterotrophic and mixotrophic nanoplankton predation on picoplankton in the Sargasso Sea and on Georges Bank. Mar Ecol Prog Ser. 192: 103-118.

Sauer T, Yorke JA, Casdagli M. 1991. Embedology. J Stat Phys. 65: 579-616.

Schallenberg M, Burns CW. 2001. Tests of autotrophic picoplankton as early indicators of nutrient enrichment in an ultra-oligotrophic lake. Freshwater Biol. 46: 27-37.

Selph KE, Landry MR, Laws EA. 2003. Heterotrophic nanoflagellate enhancement of bacterial growth through nutrient remineralization in chemostat culture. Aquat Microb Ecol. 32: 23-37.

Šimek K, Bobkova J, Macek M, Nedoma J, Psenner R. 1995. Ciliate grazing on picoplankton in a eutrophic reservoir during the summer phytoplankton maximum: a study at the species and community level. Limnol Oceanogr. 40: $1077-1090$. 
589

590

591

592

593

594

595

Šimek K, Hartman P, Nedoma J, Pernthaler J, Springmann D, Vrba J, Psenner R. 1997. Community structure, picoplankton grazing and zooplankton control of heterotrophic nanoflagellate in a eutrophic reservoir during the summer phytoplankton maximum. Aquat Microb Ecol 12: 49-63.

Śliwińska-Wilczewska S, Maculewicz J, Felpeto AB, Latała A. 2018. Allelopathic and bloom-forming picocyanobacteria in a changing world. Toxins. 10, 48.

Stemberger RS, Gilbert JJ. 1985. Body size, food concentration, and population-growth in planktonic rotifers. Ecology. 66: 1151-1159.

Stockner JG. 1988. Phototrophic picoplankton: anoverview from marine and freshwater ecosystems. Limnol Oceanogr. 33: 765-775.

Stockner JG. 1991. Autotrophic picoplankton in freshwater ecosystems: the view from the summit. Int Rev ges Hydrobiol. 76: 483-492.

Stockner JG, Antia NJ. 1986. Algal picoplankton from marine and freshwater systems: a multidisciplinary perspective. Can J Aquat Sci. 43: 2472-2503.

Stockner JG, Porter KG. 1988. Microbial food webs in freshwater planktonic ecosystems. In: Carpenter SR, editor. Complex Interactions in Lake Communities. New York (NY): Springer-Verlag; p. 69-83.

Stockner J, Callieri C, Cronberg G. 2000. Picoplankton and other non-bloom-forming cyanobacteria in lakes. In: Whitton BA, Potts M, editors. The Ecology of Cyanobacteria. Dordrecht: Kluwer Academic Publishers; p. 195-231.

Sugihara G, May R. 1990. Nonlinear forecasting as a way of distinguishing chaos from measurement error m time series. Nature. 344: 734-741.

Sugihara G, May RM, Ye H, Hsieh CH, Deyle ER, Fogarty M, Munch SB. 2012. Detecting causality in complex ecosystems. Science. 338(6106): 496-500.

Sundt-Hansen L, Olsen YA, Stibor H, Heldal M, Vadstein O. 2006. Trophic cascades mediated by copepods, not nutrient supply rate, determine the development of picocyanobacteria. Aquat Microb Ecol. 45: 207-218.

Suzuki K, Nakamura Y, Hiromi J. 1999. Feeding by the small calanoid copepod Paracalanus sp. on heterotrophic dinoflagellates and ciliates. Aquat Microb Ecol. 17: 99-103.

Takens F.1981. Detecting strange attractors in turbulence. Lect Notes Math. 898: 366381. 
621 Ushio M, Hsieh CH, Masuda R, Deyle E, Ye H, Chang CW, Sugihara G, Kondoh M.

622

623

624

625

626

627

628

629

630

631

632

633

634

635

636

637

638

639

640

641

642

643 Yoshida T, Kagami M, Gurung T, Urabe J. 2001b. Seasonal succession of zooplankton 644 645

2018. Fluctuating interaction network and time-varying stability of a natural fish community. Nature. 554: 360-363.

Ushio M, Osada Y, Kumagai T, Kume T, Pungga RS, Nakashizuka T, Itioka T, Sakai S. 2019. Dynamic and synergistic influences of air temperature and rainfall on general flowering in a Bornean lowland tropical forest. Ecol Res.

Van Donk E, Ianora A, Vos M. 2011. Induced defences in marine and freshwater phytoplankton: a review. Hydrobiologia. 668: 3-19.

Vörös L, Mózes A, Somogyi B. 2009. A five-year study of autotrophic winter picoplankton in Lake Balaton, Hungary. Aquat Ecol. 43: 727-734.

Weisse T. 1993. Dynamics of autotrophic picoplankton in marine and freshwater ecosystems. Adv Microb Ecol. 13: 327-370.

Wickham SA. 1995. Trophic relations between cyclopoid copepods and ciliated protists: complex interactions link the microbial and classic food webs. Limnol Oceanogr. 40: 1173-1181.

Ye H, Beamish RJ, Glaser SM, Grant SCH, Hsieh CH, Richards LJ, Schnute JT, Sugihara G. 2015. Equation-free mechanistic ecosystem forecasting using empirical dynamic modeling. Proc Natl Acad Sci. 112: E1569-E1576.

Yoshida T, Gurung T, Kagami M, Urabe J. 2001a. Contrasting effects of a cladoceran (Daphnia galeata) and a calanoid copepod (Eodiaptomus japonicus) on algal and microbial plankton in a Japanese lake, Lake Biwa. Oecologia. 129: 602610. in the north basin of Lake Biwa. Aquat Ecol. 35: 19-29. 
646 Table 1. Significant causal variables affecting the abundances of single-celled

647 picocyanobacteria (SPcy) and colonial picocyanobacteria (CPcy) identified by CCM,

648 and according time-averaged interaction strengths calculated by the multivariate S-map.

\begin{tabular}{llrccccc}
\hline $\begin{array}{l}\text { Effect } \\
\text { variable }\end{array}$ & $\begin{array}{l}\text { Causal } \\
\text { variable }\end{array}$ & $t_{p}$ & $\rho_{\max }$ & $\Delta \rho$ & $P_{\mathrm{z}}$ & $P_{\mathrm{s}}$ & $\begin{array}{c}\text { Time-averaged } \\
\text { interaction strength }\end{array}$ \\
\hline SPcy & Temperature & 0 & 0.75 & 0.42 & 0.000 & 0.048 & 0.164 \\
& CPcy & -2 & 0.57 & 0.46 & 0.000 & 0.004 & -0.467 \\
& HNF & -1 & 0.58 & 0.31 & 0.007 & 0.006 & 0.324 \\
& Keratella & -4 & 0.42 & 0.44 & 0.001 & 0.024 & -0.213 \\
& Polyarthra & -5 & 0.51 & 0.47 & 0.000 & 0.003 & 0.133 \\
& Trichocerca & 0 & 0.26 & 0.13 & $0.342^{*}$ & $0.081^{*}$ & \\
& Cladocera & 0 & 0.62 & 0.54 & 0.000 & 0.001 & -0.300 \\
& Copepod & -3 & 0.54 & 0.41 & 0.001 & 0.001 & 0.008 \\
\hline CPcy & Temperature & -2 & 0.91 & 0.59 & 0.000 & 0.001 & -0.299 \\
& SPcy & -2 & 0.82 & 0.57 & 0.000 & 0.001 & 0.125 \\
& HNF & -3 & 0.81 & 0.63 & 0.000 & 0.001 & 0.212 \\
& Keratella & -4 & 0.49 & 0.47 & 0.000 & 0.011 & -0.059 \\
& Polyarthra & 0 & 0.12 & 0.16 & $0.267 *$ & $0.309 *$ & \\
& Trichocerca & -1 & 0.47 & 0.30 & 0.019 & 0.004 & 0.262 \\
& Cladocera & -1 & 0.29 & 0.29 & 0.040 & 0.044 & -0.081 \\
& Copepod & -6 & 0.55 & 0.45 & 0.000 & 0.002 & 0.139 \\
\hline
\end{tabular}

$649 t_{p}$ : cross-map lag; $\rho_{\max }: \rho$ at maximal library size; $\Delta \rho: \rho$ at maximum library size minus $650 \rho$ at minimum library size; $P_{\mathrm{z}}: P$ value of Fishfer's z test; $P_{s}: P$ value of surrogate test; *: 651 not statistically significant at the 0.05 level. 
653 Figure 1. Seasonal changes in vertical profiles of (a) water temperature and (b) 654 chlorophyll- $a$ concentration.

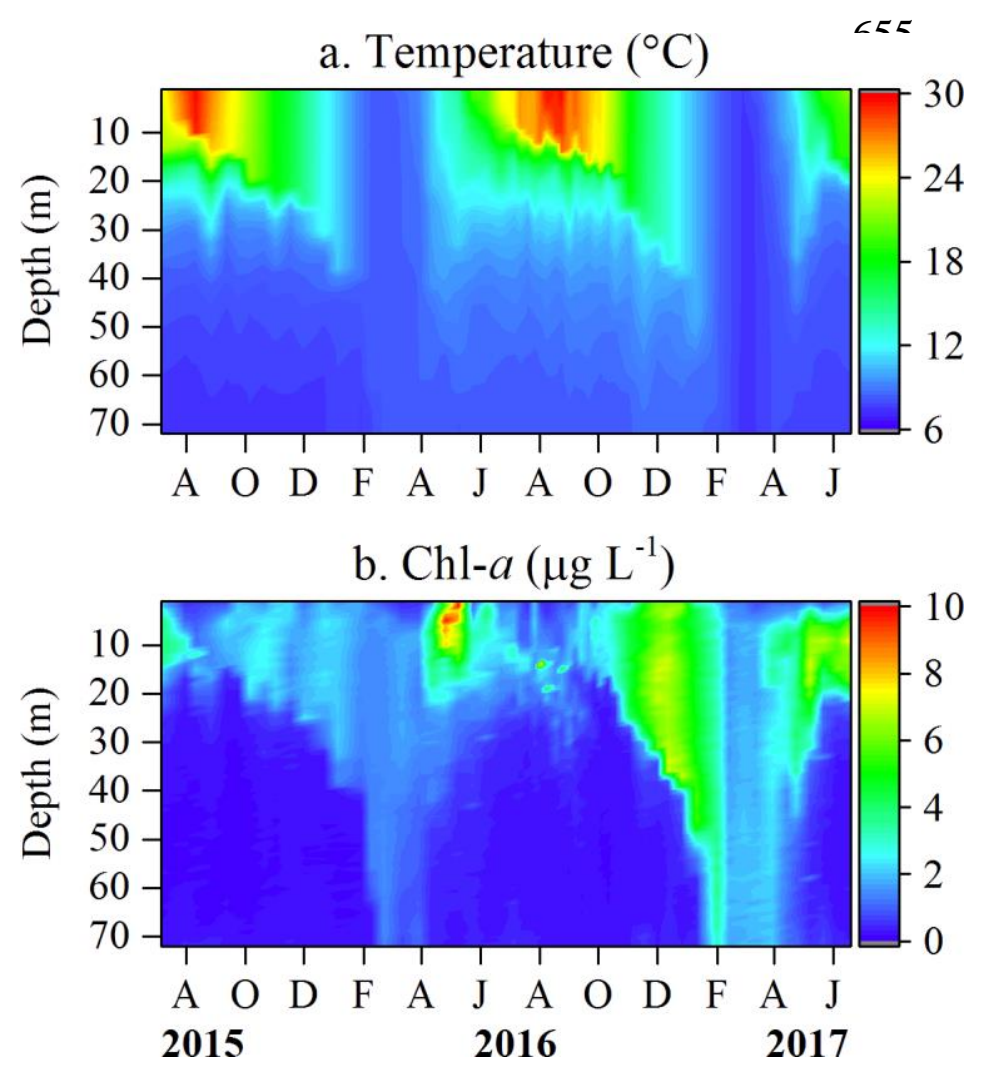


662 Figure 2. Seasonal changes in vertical abundances of (a) single-celled picocyanobacteria 663 (SPcy) and (b) colonial picocyanobacteria (CPcy).

664
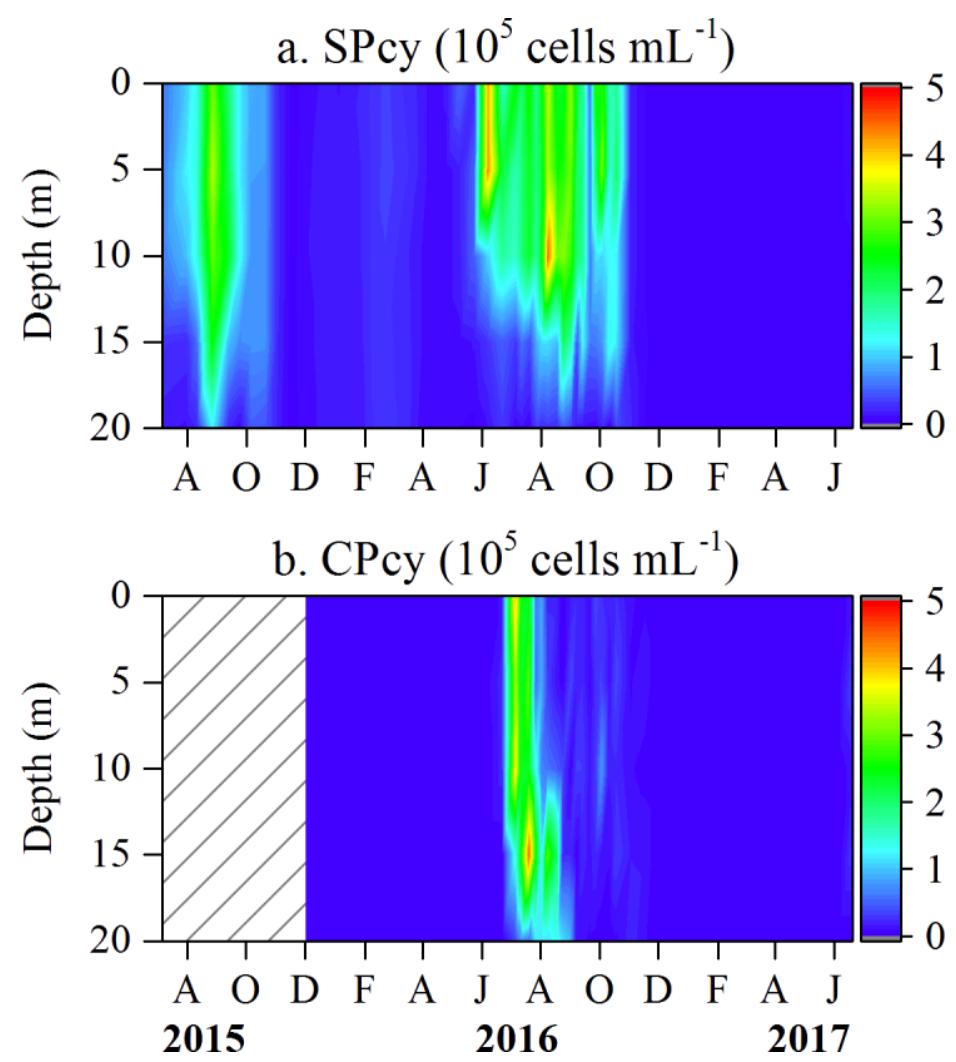
665 Figure 3. The effects of causal variables on picocyanobacterial abundance determined

666 using the multivariate S-map. The boxplots show the interaction strengths of causal

667 variables on the abundances of (a) SPcy and (b) CPcy. The bottom and top of each box

668 show the lower (25\%) and upper (75\%) quartiles, respectively; the band and square

669 within each box represent the median and the mean, respectively; whiskers indicate the

670 minimum and maximum; and crosses represent outliers. Note that original time series

671 were standardized, and thus the interaction strengths from different variables can be

672 compared directly to discuss the relative importance of each variable.
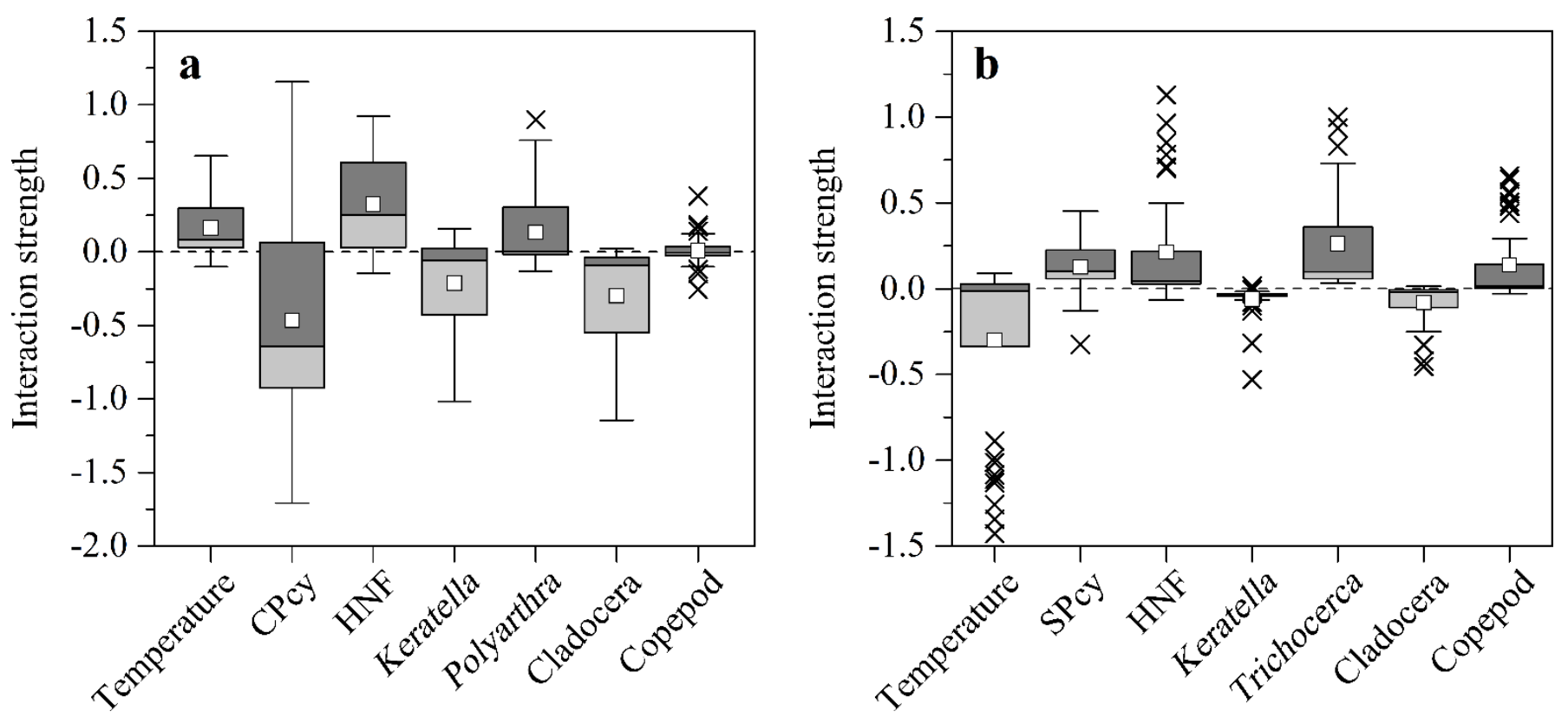

673

674 
675 Figure 4. The effects of grazers on picocyanobacterial abundance, and the relationship

676 between SPcy and CPcy. Numbers beside the arrows represent time-averaged values of 677 interaction strengths.

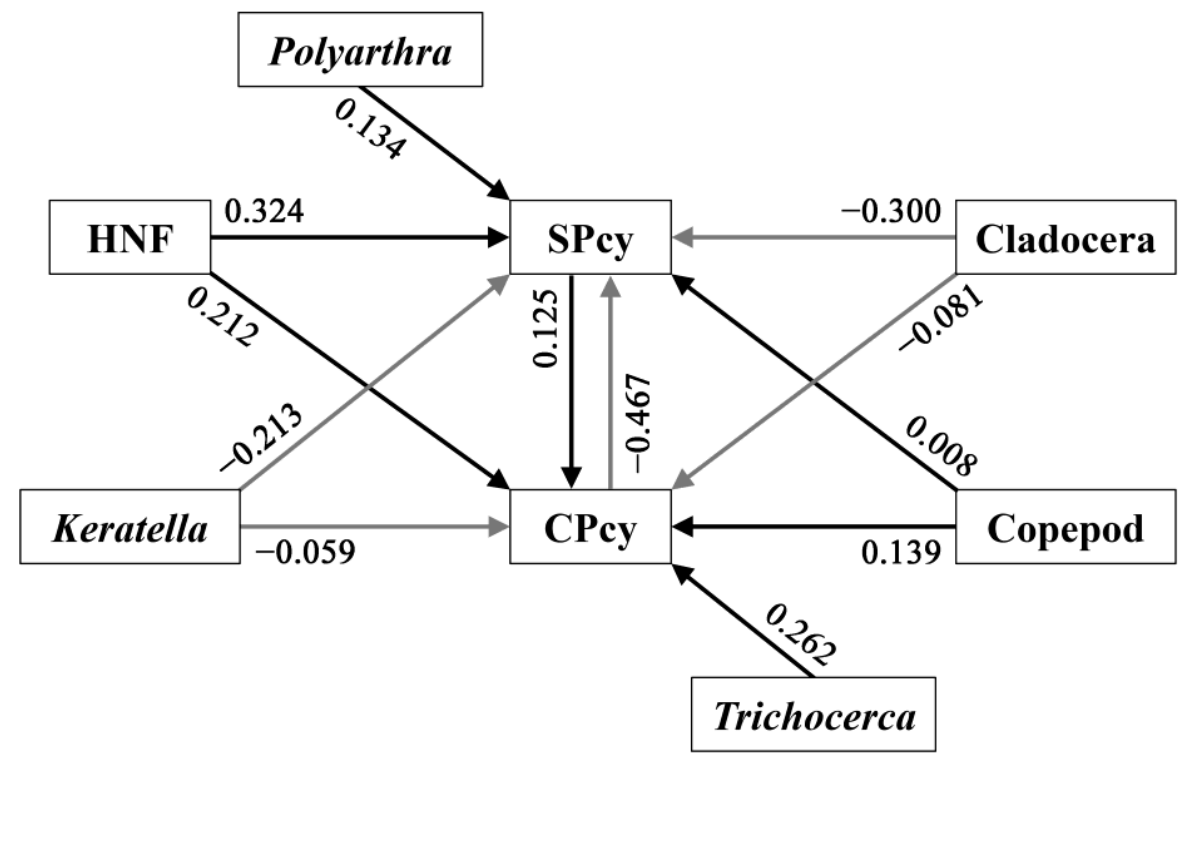


681 Table S1. Optimal parameters of the multivariate S-map.

\begin{tabular}{lcccccc}
\hline $\begin{array}{l}\text { Variable } \\
\text { to predict }\end{array}$ & $\theta$ & $\begin{array}{c}\text { Number of } \\
\text { predictions }\end{array}$ & $\rho$ & MAE & RMSE & $P$ value \\
\hline SPcy & 3.75 & 36 & 0.90 & 0.28 & 0.46 & 0.000 \\
\hline CPcy & 1.45 & 35 & 0.65 & 0.43 & 0.86 & 0.000 \\
\hline
\end{tabular}

$682 \theta$ : the nonlinear parameter; $\rho$ : the forecasting accuracy; MAE: mean absolute error;

683 RMSE: root mean square error; $P$ value: $P$ value that $\rho$ is significantly greater than zero

684 using Fishfer's z-transformation.

685 
686 Table S2. Significant causal variables affecting the abundances of HNF and metazoan

687 zooplankton identified by CCM, and according time-averaged interaction strengths 688 calculated by the multivariate S-map.

\begin{tabular}{|c|c|c|c|c|c|c|c|}
\hline $\begin{array}{l}\text { Effect } \\
\text { variable }\end{array}$ & $\begin{array}{l}\text { Causal } \\
\text { variable }\end{array}$ & $t_{p}$ & $\rho_{\max }$ & $\Delta \rho$ & $P_{\mathrm{z}}$ & $P_{\mathrm{s}}$ & $\begin{array}{l}\text { Time-averaged } \\
\text { interaction strength }\end{array}$ \\
\hline \multirow[t]{4}{*}{$\mathrm{HNF}$} & SPcy & 0 & 0.63 & 0.30 & 0.007 & 0.045 & -0.002 \\
\hline & CPcy & -5 & 0.55 & 0.53 & 0.000 & 0.013 & -0.119 \\
\hline & Polyarthra & -3 & 0.27 & 0.30 & 0.033 & 0.046 & -0.297 \\
\hline & Cladocera & -1 & 0.51 & 0.53 & 0.000 & 0.004 & -0.058 \\
\hline \multirow[t]{4}{*}{ Keratella } & CPcy & -6 & 0.48 & 0.42 & 0.001 & 0.017 & 0.483 \\
\hline & $\mathrm{HNF}$ & 0 & 0.30 & 0.26 & 0.047 & 0.036 & 0.072 \\
\hline & Polyarthra & -5 & 0.27 & 0.32 & 0.023 & 0.046 & -0.142 \\
\hline & Cladocera & -2 & 0.26 & 0.32 & 0.023 & 0.027 & 0.024 \\
\hline \multirow[t]{2}{*}{ Polyarthra } & $\mathrm{HNF}$ & -3 & 0.40 & 0.36 & 0.007 & 0.030 & -0.035 \\
\hline & Cladocera & -5 & 0.77 & 0.60 & 0.000 & 0.001 & 0.331 \\
\hline \multirow[t]{5}{*}{ Trichocerca } & CPcy & 0 & 0.51 & 0.49 & 0.000 & 0.009 & -0.091 \\
\hline & $\mathrm{HNF}$ & -5 & 0.51 & 0.52 & 0.000 & 0.028 & 0.417 \\
\hline & Cladocera & -5 & 0.63 & 0.59 & 0.000 & 0.001 & -0.006 \\
\hline & Copepod & -2 & 0.56 & 0.58 & 0.000 & 0.045 & 0.083 \\
\hline & Polyarthra & 0 & 0.30 & 0.33 & 0.017 & 0.042 & 0.436 \\
\hline \multirow[t]{4}{*}{ Cladocera } & CPcy & -6 & 0.53 & 0.51 & 0.000 & 0.017 & 0.170 \\
\hline & $\mathrm{HNF}$ & -2 & 0.39 & 0.34 & 0.011 & 0.049 & 0.273 \\
\hline & Polyarthra & -6 & 0.55 & 0.37 & 0.002 & 0.006 & 0.400 \\
\hline & Trichocerca & -1 & 0.46 & 0.25 & 0.046 & 0.004 & -0.154 \\
\hline \multirow[t]{3}{*}{ Copepod } & SPcy & 0 & 0.56 & 0.39 & 0.001 & 0.003 & 0.321 \\
\hline & Cladocera & 0 & 0.34 & 0.36 & 0.009 & 0.009 & 0.062 \\
\hline & Trichocerca & -2 & 0.44 & 0.36 & 0.006 & 0.003 & -0.317 \\
\hline
\end{tabular}

$689 \quad t_{p}$ : cross-map lag; $\rho_{\max }: \rho$ at maximal library size; $\Delta \rho: \rho$ at maximum library size minus $690 \rho$ at minimum library size; $P_{\mathrm{z}}: P$ value of Fishfer's z test; $P_{s}: P$ value of surrogate test.

691

692 
693 Figure S1. Seasonal changes in vertical distributions of (a) dissolved inorganic nitrogen 694 (DIN) and (b) dissolved inorganic phosphorus (DIP) concentrations.

695
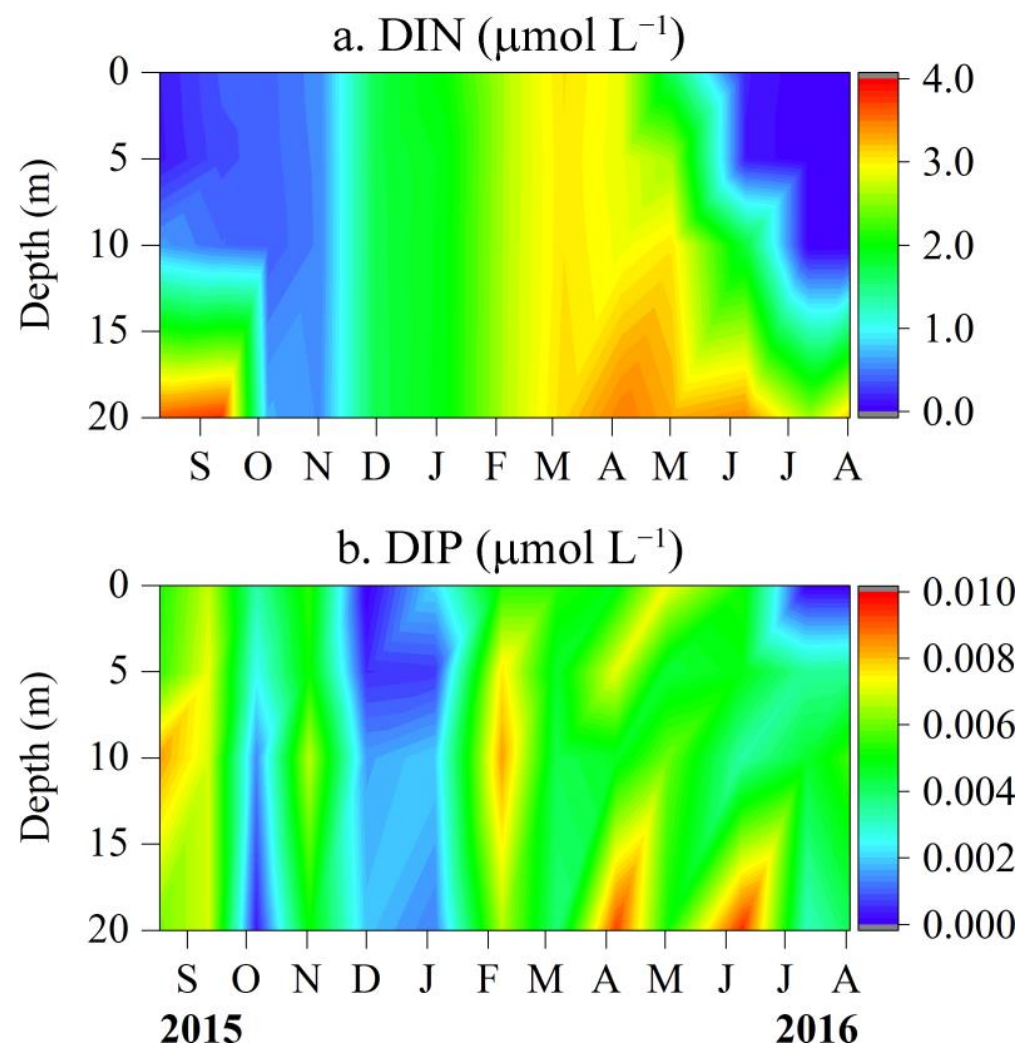
697 Figure S2. Seasonal changes in vertical abundances of picocyanobacteria grazers: (a)

698 HNF, (b) ciliate, (c) rotifer, (d) cladocera, and (e) copepod.

699
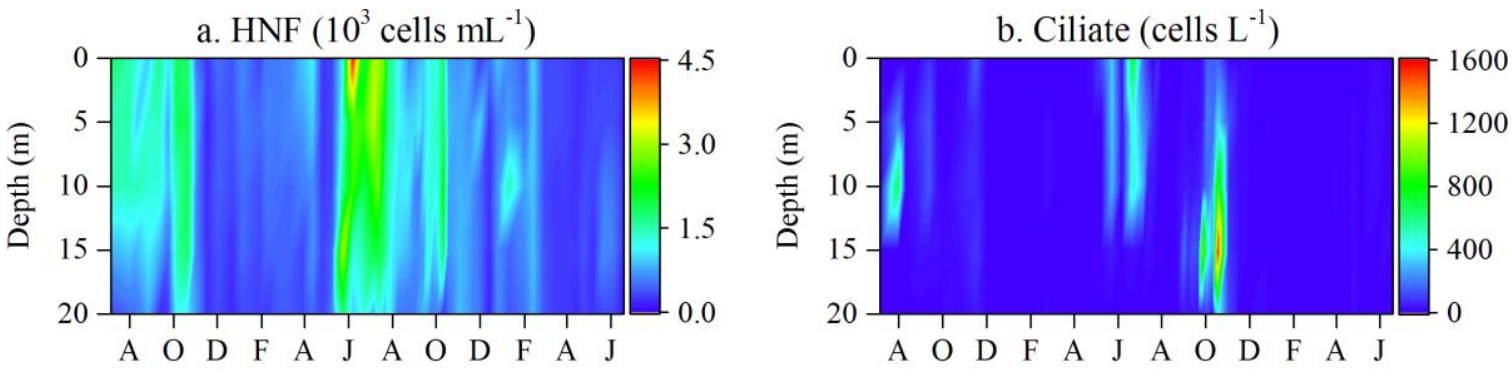

c. Rotifer (individuals $\mathrm{L}^{-1}$ )
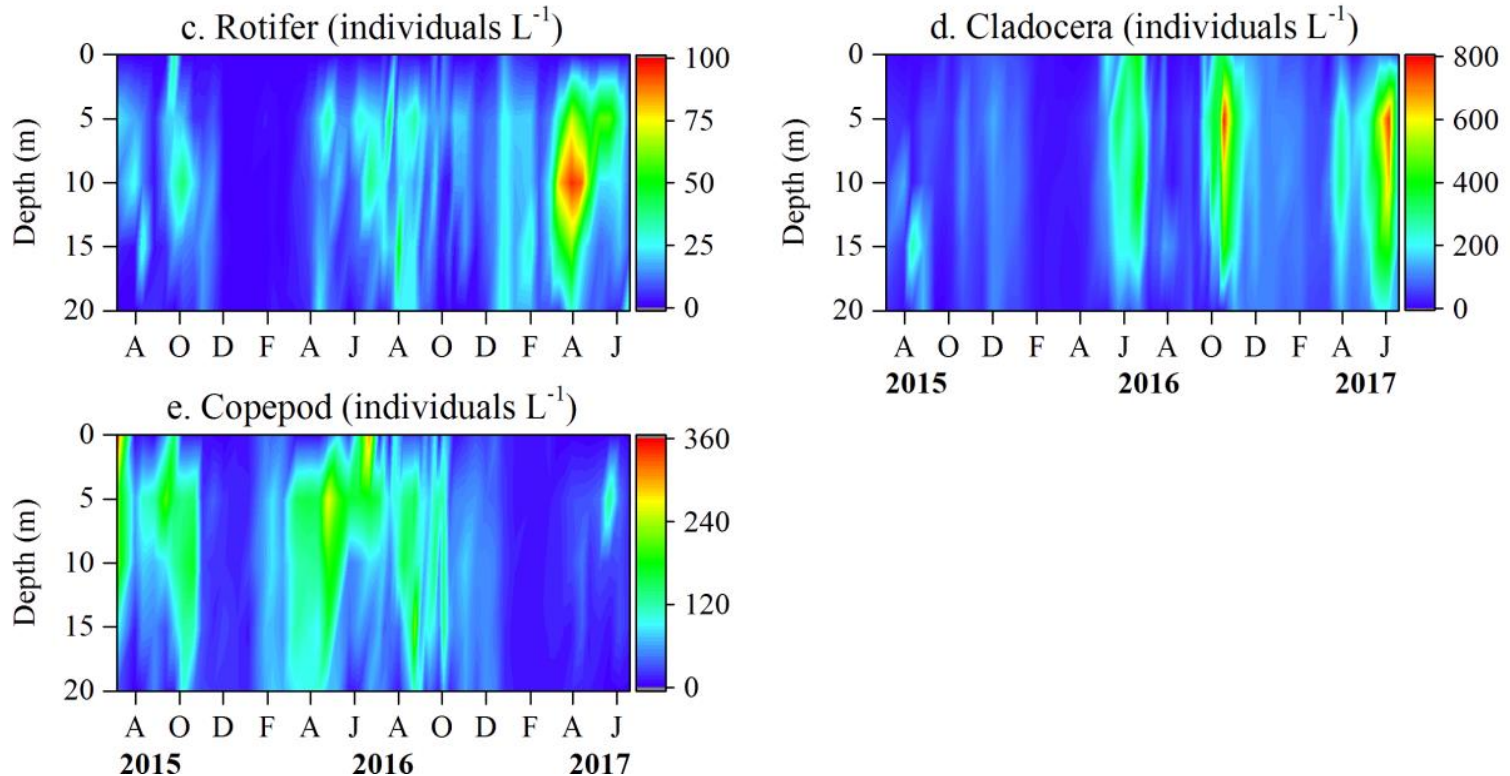
700 Figure S3. Seasonal changes in the genus-level composition of rotifers.

701

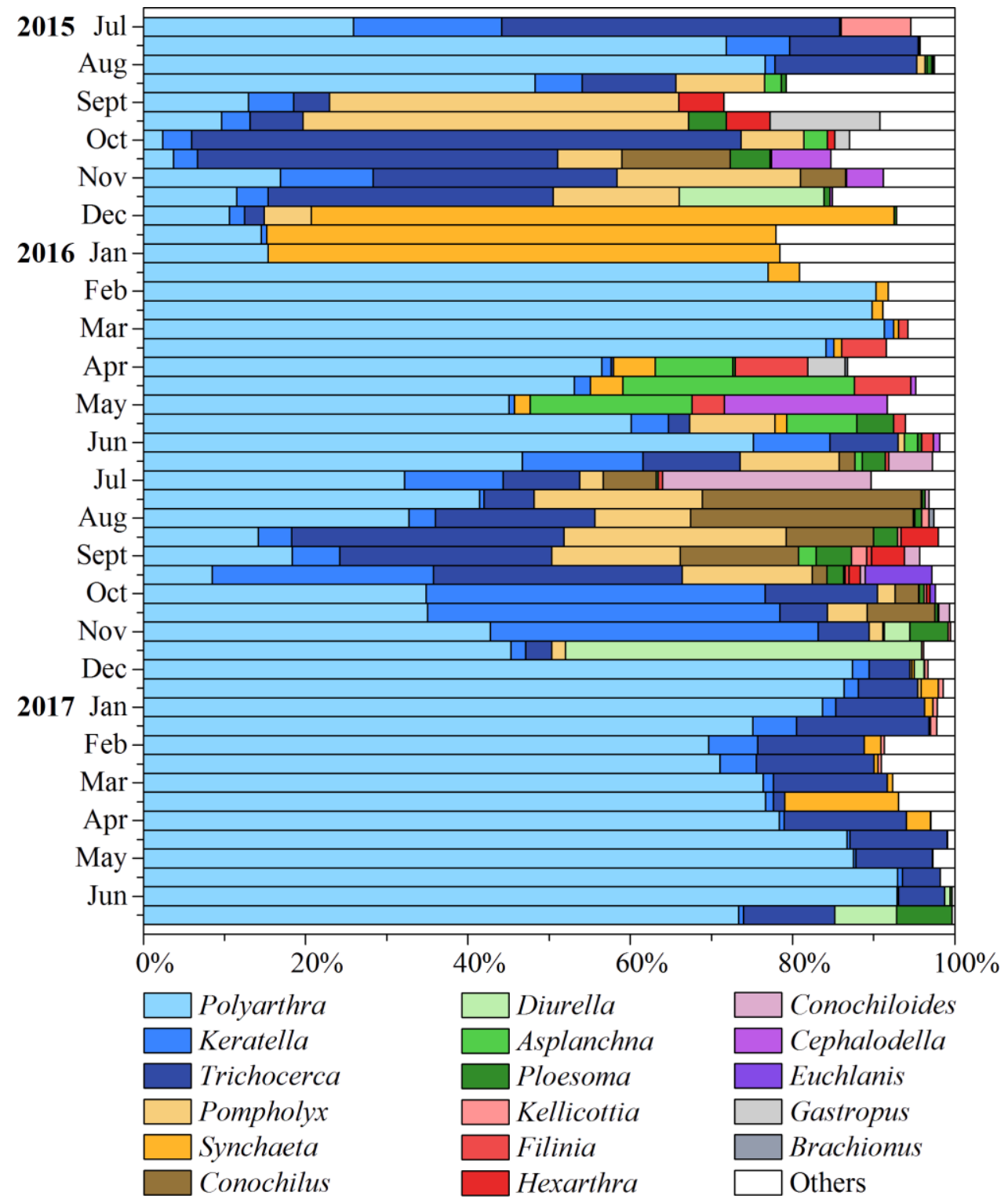


705 Figure S4. Time-delayed convergent cross mapping (CCM). (a) SPcy and (b) CPcy

706 cross-mapping causal variables. Crossed dash lines indicate the optimal cross-map lag $707\left(t_{p}\right)$, which maximizes cross map skill $(\rho)$.

a)
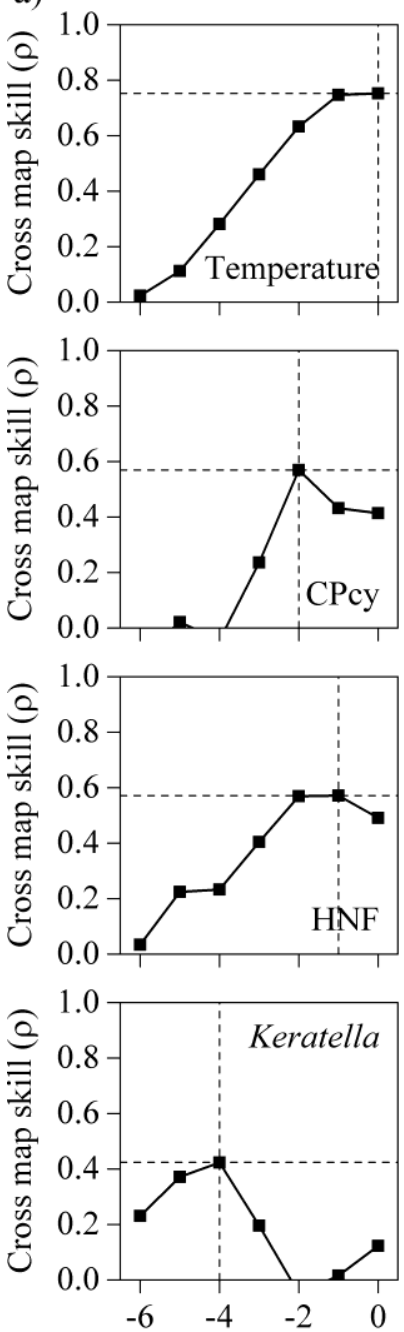

Cross-map lag
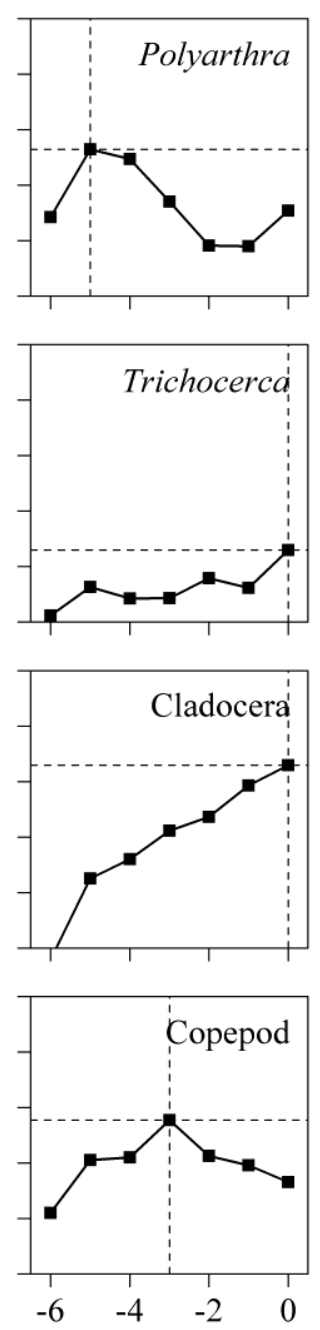

Cross-map lag b)
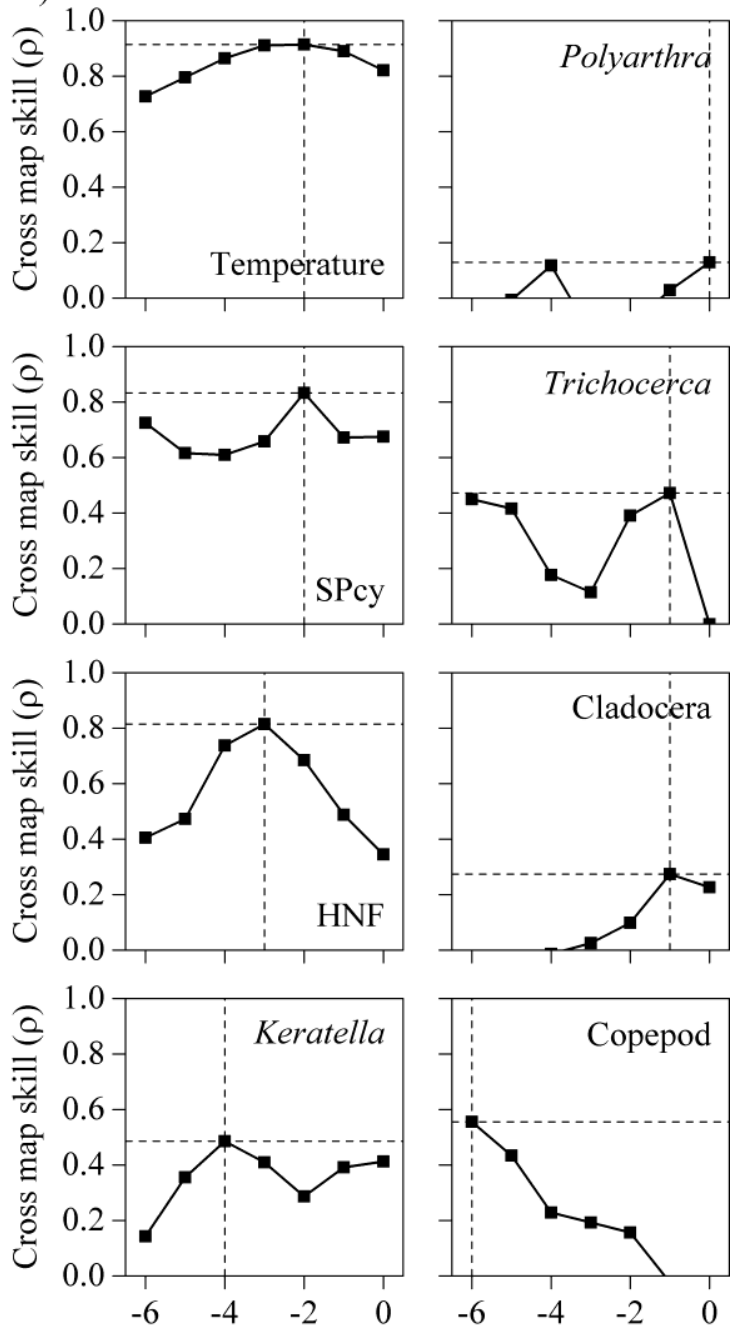

Cross-map lag

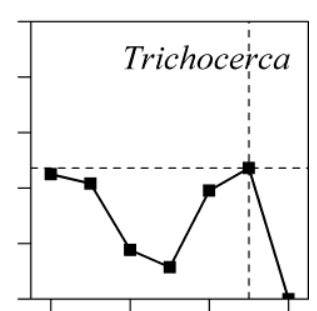

Cladocera
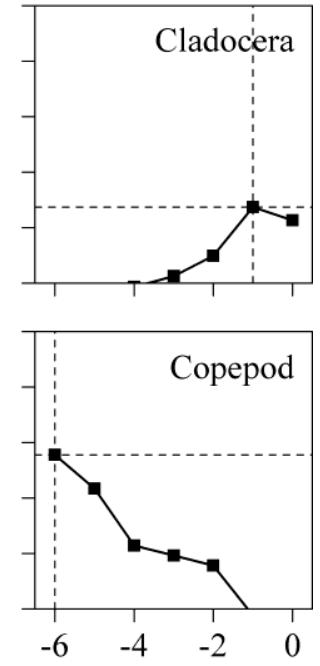

Cross-map lag 
710 Figure S5. CCM at the optimal cross-map lag. (a) SPcy and (b) CPcy cross-mapping

711 causal variables

712

a)
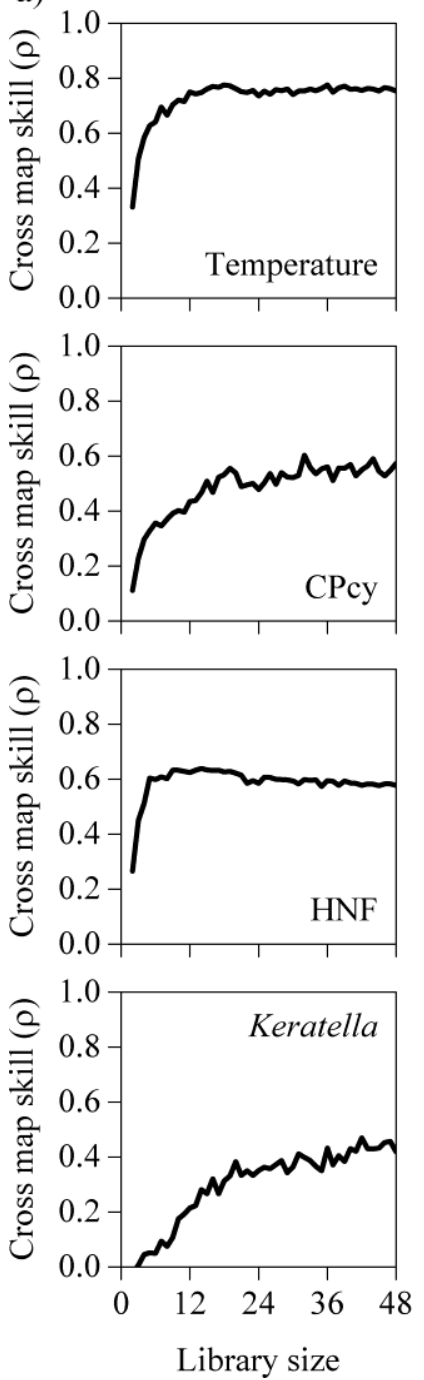

713

714 b)
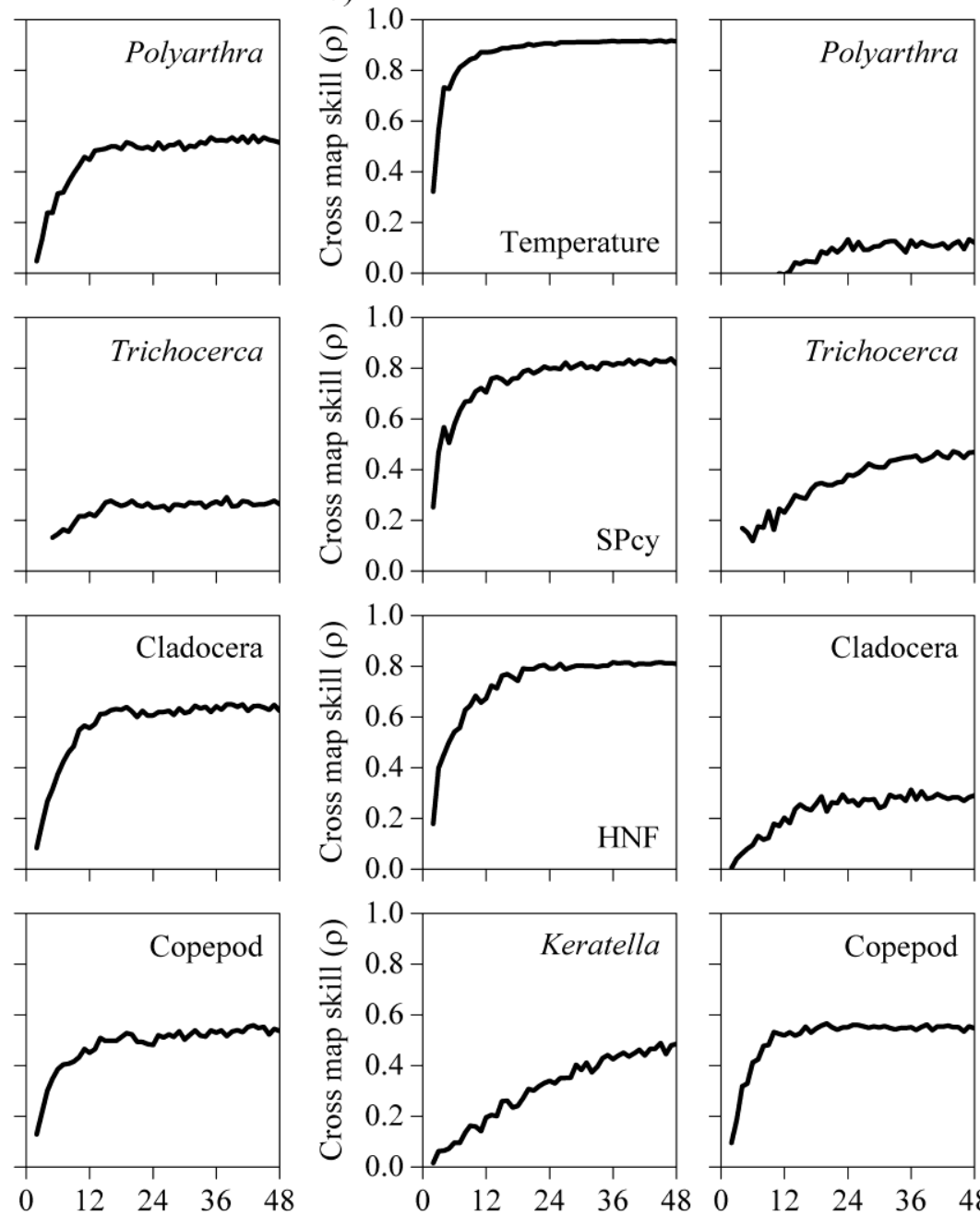

Library size
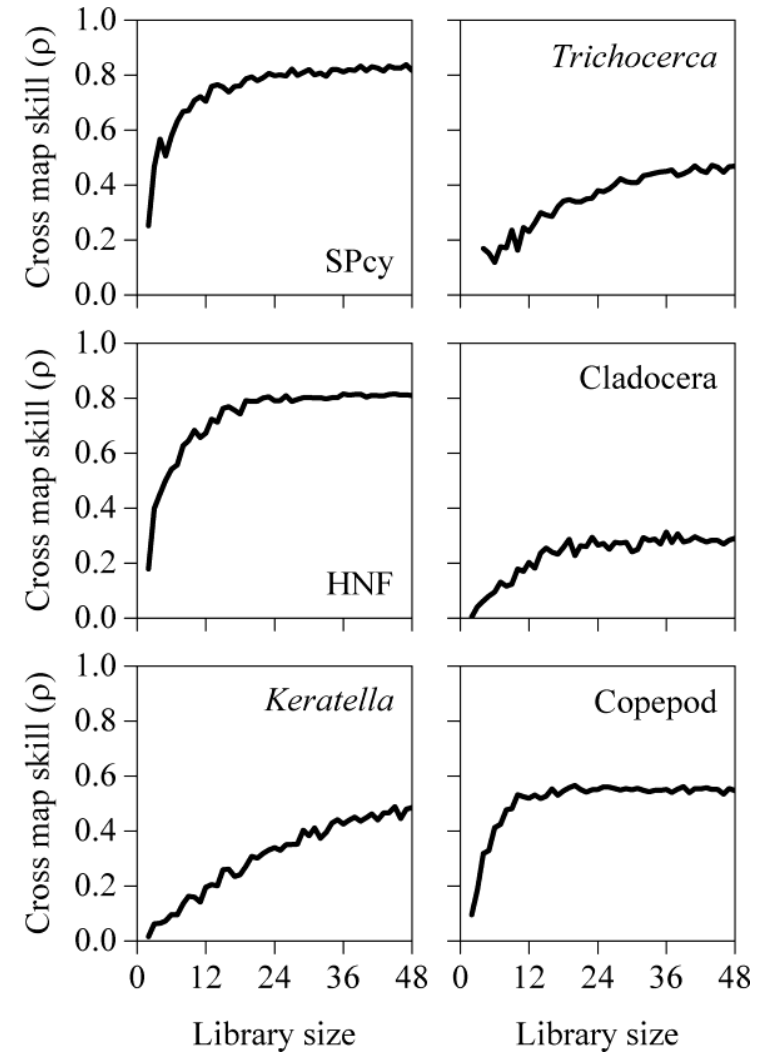

Library size 